\title{
CULTURAL AND PSYCHOLOGICAL APPROACH TO THE PHENOMENON OF LONELINESS
}

\author{
Mullaboyeva Nargiza Sharopaliyevna, \\ Senior teacher, Namangan Engeneering - technology institute, \\ Namangan, Uzbekistan
}

http://dx.doi.org/10.26739/2573-5616-2018-3-1-4

\begin{abstract}
The article deals with loneliness as a socio-psychological phenomenon. However, given psychological mechanisms of manifestations, the formation of loneliness in young people. gives a detailed account of the problem of loneliness by philosophers and religious figures. Scientists, representing almost all philosophical schools and trends, have shown that they try to explore the phenomenon of loneliness in their scientific worldview.

Key words: phenomenon, genesis, loneliness, depression, family, individualism, socialization, fear.
\end{abstract}

$\mathrm{T}$ he phenomenon of loneliness is complex, it is represented in several ways, and people are different.

The scientific conception of this concept has certain difficulties because the cultural-historical and psychological forms of loneliness in the history of mankind and the societies have maintained a specific attitude towards it.

The phenomenon of "loneliness" has been studied for several decades by different sciences. And each, whether it be philosophy, psychology or sociology - has its own view on this problem. In this case, we are interested in the psychological basis of loneliness as a socio-psychological phenomenon.

Analyzing the work of domestic and foreign authors (M. Mead, RS Weiss, WA Sadler, NE Pokrovsky, RS Nemov, EE Rogova, KI Kutron, G.M. Tikhonov, RS Nemov), we can distinguish the following:

- people live by experiences, emotions. Important aspect of self-awareness and the above experience, as well as the degree of significance of loneliness for the person (VS Vasilyuk);

- a person can experience loneliness due to poor adaptability to the surrounding world, sheltering his inner feelings from him (K. Rogers, J. Moore);

- the basis of the phenomenon of loneliness is the general circle of experiences, since it is experienced by all people (RS Weiss, M. Mead);

- E.E. Rogova distinguishes five types of loneliness:

1) temporary (situational); 
2) constant;

3) emotional;

4) behavioral;

5) cognitive loneliness.

Recognition of the rights of each individual being recognized is a sign of a positive upward trend in the life of the community, and may also occasionally lead to some negative circumstances. Granting economic, social and political freedom to the members of the society creates a basis for people to live separately and solve their own problems. This created a sense of individualism and led the way towards loneliness.

The only person who is depressed and depressed is that he has a lack of communication skills and skill. The only person who sees himself as a less attractive, someone who does not love and does not respect. This kind of attitude creates feelings of special negative feelings such as hatred, grief, and misery. Lonely people avoid self-esteem. It has the feeling of fear, anxiety, and frustration.

Individuals are pessimistic about others. They look at them with pity, lonely people speak less, do not like to draw attention to others.

Looking at the history of humanity, we can see that there is always a problem of solitude, as psychology develops, so it is possible to observe different interpretations of loneliness, such as the following forms of loneliness:

- Raising loneliness through customs, ceremonies.

- Punishment with loneliness - persecution. The social limitation of individual at different stages of society's development was considered to be the most severe punishment.

- Volunteering loneliness - to make a world of spirits. "To make a world of self-denial, to abandon the desires of Allah and to abandon the path of Allah." The purpose of such loneliness is to purify one's heart, to attain spiritual maturity.

- Volunteering loneliness - to make a world of spirits. "To make a world of self-denial, to abandon the desires of Allah and to abandon the path of Allah." The purpose of such loneliness is to purify one's heart, to attain spiritual maturity.

In western culture, the feeling of loneliness is a necessary condition for the formation of a person, the second aspect of the problem of experiencing it, receiving spiritually is the need to find a beloved person, a desire to communicate, and a sense of personality. Man lives up to his loneliness, but no one should think that he is alone. This is typical of western life.

Ethnic norms and sense of duty dominate the people of the East. The basis of society is small social groups (family, relatives), a person is a member of a group based on common interests, protects its interests and 
adheres to its rules. A distinctive person in Oriental culture is traditionally subordinate to the social consciousness of the society. It is acknowledged as the highest value for the family and for the family, for the sake of service and honor and dignity.

Looking at the life and work of our great fellow man and poet ZM Bobur, he fought for his family, but the internal treachery was forced to leave the homeland for contradictions. Babur's farewell to his homeland causes him to experience spiritual loneliness. We can see it in the ghazals and rubies of his work.

\section{M: I did not find any other sweet heart, I did not find a hell of a mystery. I have not seen a soul other than my soul, I do not see anybody in my heart.}

As a result of fundamental differences in Western-Christian and EastAsian cultures, K.G.Yunning finds the archetypes of the original (extravert and introvert) person.

The western world, oriented towards individualism, tries to soften the striving to separate individuals.

The Oriental Oriental culture, in contrast, creates conditions for selfexpression and self-reliance.

In world religions, there is a different interpretation of solitude.

On the one hand, loneliness is a punishment or a tragedy. In particular, the Bible and the Qur'an describe the man being thrown out of Paradise for the sins of man (angel).

On the other hand, positive aspects of loneliness in almost all religions are also mentioned. This is especially evident in Christianity and Buddhism, with all its sins being forgiven and repentant. The person who refused to be with the people, but who made himself contact with God does not mean alone.

In Christianity, loneliness is defined as a specific form of resorting to a god, and being alone with God plays an important role in the spiritual development of man. In the human society, people who do not share their lives with people around the world often adhere to religious doctrines and choose the worship of repentance.

In the medieval ages the specific views of these concepts have emerged, in which loneliness is interpreted as spiritual purification, freedom, joy. That's why the concept of loneliness is a social-psychological phenomenon. The romantic, who lived in the 18th century, accepted loneliness as their motto. They preferred to live alone because of the difficulties of life in the world of the human race. Scientific understanding of the problem of loneliness begins with the second half of the 19th century. 
Philosopher, writer Henry Toro described his own vision of the 19th century loneliness problem, which he described as the first step towards solving loneliness. As Adam grows alone, he promotes his idea of enriching his inner world and analyzing his behavior.

Henry Toro looks at loneliness as a means of protecting one's personality. "Man's loneliness is spiritually enriched, morally enriched and serves to socialize," he wrote.

Henry Cerkegor, the contemporary of Henry, argues differently about the problem of loneliness: "A person's inner world is a process that no one else can interfere with," he calls people to believe in God, but these views are different from the traditional ones; , it is not necessary to be alone, for man is born before birth ...

European philosopher Edmund Gusserl supports the views of Kerkegor, the philosopher of the late 19th and early 20th centuries, believes that loneliness is a distinctive phenomenon. All the events that are out of the mind are images reflected in human consciousness, and consider that there is a transient strangulation and loneliness between man and the outer world.

In the 20th century, Jean Paul Sartre described the problem of loneliness as the main idea of his creativity. According to Sartre, "as long as a person tries to understand himself, he goes out of his own way, but life does not give the human being such a chance." "People lose their hope and confidence in the process of social relations, and the sense of loneliness is the basis of human life," says Sartre.

B. Miyushkovych tries to disclose this problem in his article "Loneliness" and analyze the science in this process, based on the theory of scientist $\mathrm{Z}$. Freud.

B. Miyushkovych "children are afraid of darkness, because this is a loneliness". People are afraid of loneliness in their minds and in their imagination, not fear of falling asleep and not waking up again. "In his opinion, loneliness is not a disease, but both medical and social, in a person's inner world, available.

Martin Buber concludes in his article "Human Problems, Prospects". "The human being at the same time feels alone as a man (as a child who has been rejected) in a vicious personhood."

Odi Dj.Relf, a scientist who has deeply analyzed the phenomenon of loneliness, describes his own view in his work "Adam - the only creature, the biological roots of loneliness." It is necessary to differentiate the longterm success of the person with the sole survival. Sometimes there is no harm in staying alone, but if this continues chronic, this leads to a psychological pathology. Often alone, people who are alone are not loved by their loved ones and, conversely, having close association with those 
who do not like it may intensify loneliness. "Psychological loneliness is in the form of non-contact, indifference to personality, and avoidance of human relationships, which is characterized by low level of coma, weakness and depression."

Scientists who have been described above think of the phenomenon of loneliness as a negative phenomenon in human life in their scientific works. These scientists analyze loneliness in the context of economic relations with regard to emotional, social, and social constraints.

the 20th century, there was a general idea that human relations in the western states developed under the influence of the individual's personality. Individuals who are unable to communicate often have negative effects on social relationships, such as being alone alone, can lead to lifestyle and negative emotions.

American psychologist Margaret Mid speaks of loneliness as an important characteristic. Children in the American family are taught very early independence. Sleep alone is the first step on the way. American children are sometimes used to experience loneliness independently. If a person does not find his place in society, and if he does not feel sympathy, it can lead to serious psychological problems. As a result, a person feels alone. Scientists, representing almost all philosophical schools and trends, have tried to cover the phenomenon of loneliness in their scientific worldview. E.Fromm, K. Horn, V.Frank1, J.P.Sartr, A.Kashyu, A. Kirkerkor, K.Yaspers and others have conducted research on the problem of loneliness.

J. S. Seartr considers loneliness as the basis of his own lifestyle, he sees the universe individually, and writes that man comes alone to the world and goes alone.

In the twentieth century, the views of D. Resman began to spread in the United States. The scientist tries to analyze the signs of social isolation, the means of isolation in his "Lonely Column". The first sign of social constraints is boredom, aggression, environmental degradation, and so on.

P. Hallus explains the human loneliness in his book, The Restraint and Solution. "Human nature is a biological entity, it is independent in social groups, it is instinct in human consciousness." As we analyze the sense of consciousness of the tragic loneliness of the 20th century, in this period, the concept of loneliness, The idea that anti-loneliness is one of the propagandist's philosopher and social psychologist, Eriks Fromm, describes the sense of fear that man has to be alone as a characteristic of human psychology. Rih Fromm writes in his book "Escape From Solitude": "The person who feels loneliness is in a difficult situation. The ability to receive emotional satisfaction from social communication is limited and people are isolated. Man experiences loneliness fear and mental disturbances in 
people who feel extremely lonely. It also identifies social needs that shape the person's negative attitude towards loneliness.

There are two types of loneliness problem: one-dimensional and multidimensional approach. In a one-dimensional approach, loneliness is perceived as an entire phenomenon. In this approach, the intensity of loneliness is a key measure of measurement. In a multidimensional approach alone, loneliness is perceived as a multifaceted phenomenon, and the focus of this approach lies in the difference in the individual's loneliness. Within this approach a number of methods have been developed. In particular, Eddie (1961) created a shaft of 24-point loneliness that expresses the intensity of the different levels. Examiners evaluate themselves and their ideals in these paragraphs and represent their perceptions of what is happening around them. In addition to this scale, similar scales for the study of loneliness were developed by Sezinbey (1964), Bradley (1969) and Yang (1979).

The most widely used loneliness scale was developed by Daniel Rassel and his staff, L.Peplo and M. Ferguson, within a one-dimensional approach. It consists of 10 positive and 10 negative items.

In my experimental-test part, I used this methodology, which was revised by Uzbek psychologists. In it, the calculation of the indicators was unified, valid and viable.

The methodology is called the "Loneliness Measurement Scale". We have used this method in our research to identify the phenomenon of loneliness in adolescents who are indifferent to loneliness.

In addition to this, we have also used methods like "Psychological Relationship Scale", "Determination of Communication Level" and "Who am I in this world?"

We have tried to identify the phenomenon of loneliness of adolescents growing up in the urban environment and in the rural environment, as we have mentioned in our introduction, and in part, I think we have seen the difference.

Methods of learning subjective subjective perception of loneliness. "(Modified scale of loneliness measurement). Before carrying out this methodology, we have given the examiners the following instructions: "Show how often you feel the situations listed below. For this purpose, put one of the points that corresponds to one of the answers in "never," "rarely," "sometimes," and "frequently". " (Annex 1)

Points scored for the answers to the total points of the Scale will be determined by adding the points. The maximum loneliness is 80 points.

The study found three levels of loneliness:

Level 1 is a high level of loneliness, a high incidence of loneliness at least one of the factors (54-80 points) 
Level 2 - the average level of loneliness, the ability to compensate for the lack of individual social and psychological relationships and weaken loneliness ( $28-53$ points)

3 degrees - low level of loneliness, absence of feeling of severe loneliness (0 - 27 points).

Qualitative analysis of the results should focus on the level of psychological relationships with others. Based on the "lone scale", you can evaluate the three dimensions of this communication:

1. "Like" - emotional component.

2. "Understand" - cognitive component.

3. "Accept" - social component.

Given that the amount of scores and scores are not equal to each size, it is necessary to calculate the average arithmetic value for all dimensions to ensure the integrity of the results.

High scores on the third dimension determine the peculiarity of the "external" psychological relationships and helps to identify the existence of external immorality.

High scores on the first and second dimensions determine the peculiarity of the "internal" psychological relationships and help to identify the existence of internal alienation.

Research on the measurement of loneliness is a high correlation between the results of these scales and the following indicators: aggravation of selfesteem and self-esteem, anxiety and autism, depression, alienation and frustration.

The quantitative indicators obtained from these scales can be summarized by summarizing the answers given by the respondents to 20 questions, which are used as methodological guidelines.

Analysis of the results shows that the general level of loneliness in urban and rural youth is high in the level of loneliness in 44 (urban teenagers) in 55\%, 48 (rural) adolescents, $21.2 \%$ (urban teenagers) by $26.2 \%, 18$ (rural youth), 21.6\% had a moderate level of loneliness, 15 (urban teenagers) $18.7 \%$, and $13.8 \%$ (rural youths) $17.8 \%$ had a low level of loneliness.

According to the results of the research, $92 \%$ of the examiners, $57.8 \%$, have a higher incidence of loneliness (from 54 to 80). As it turned out, the adolescent is no longer "a young boy," but now he is "a great man." The older man must be independent, and he must solve his problems himself. In this period, appealing to adult care is condemned by peers, and the adolescent does not want it. During this period, adolescents are treated as adults by the kind of compliments they have in the past. They no longer "like" admiration and admiration for the "little things" of adults. Now they try to be the best of emotional support and to solve their problems personally. 
When they first asked for help from their parents in the street, in the garden, in the garden, in the garden, when they heard from someone outside the family and tried to beat their parents, they do not want to interfere. All of these are symptoms of emotional autonomy that are directly observed in adolescents. Another of the autonomy observed in adolescents is the Mekan autonomy. As a result, adolescents try to stay alone in their own room, stay alone as far as their job is, or stay out of place, especially when they are away from their parents, family members, and busy themselves with their own thoughts. Even though they are conversing, their peers often communicate with their peers, and with their parents, they tend to be less likely to communicate. At the same time, some parents who are unaware of the real cause of adolescents are worried about their situation and are more interested in them than before.

Thus, the problem of the person's limitation of the community, the occurrence of a loneliness, the possibility of communicating with God, or the spiritual well-being of others, were also actual in the past. Man is alone in God. Participation in social relations, participation in family, kindergarten, school and other social institutions helps to solve the problem of loneliness.

\section{References}

1. Byachkova, N.B. The phenomenon of loneliness: the philosophical and anthropological analysis: Author's abstract. dis. Cand. philos. Sciences-Perm, 2006

2. Verbitskaya S.L. Socio-psychological factors of experiencing loneliness. Author's abstract. Cand. psychol. Sciences of St. Petersburg., 2002.

3. Karimov I A " Highly qualified professionals are the key to development ". - T. Uzbekistan, 1995.

4.Myuskovich B.Loneliness: interdisciplinary approach, the Maze of loneliness, (comp., Obshch., Ed., And predisl. Pokrovsky N.E.), 2002.

5. Korchagina S.G. Genesis, types and manifestations of loneliness Moscow: Moscow Psychological and Social Institute, 2005.

6. Puzko V.I. Existional neurosis as escape from loneliness, Materialy of the scientific conference "Theology, Philosophy and Psychology of Solitude" Vladivostok, 2005.

7. Rutman E. Nobody understands me. // Family and school. 1996. № 9.

8. Starshenbaum G.V. Love against loneliness. - M., 1991. 